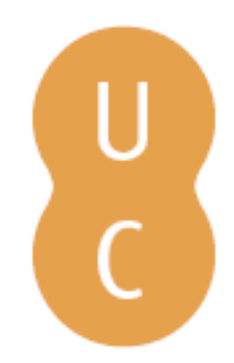

\title{
nommalina
}

\section{Da Historia Apollonii Regis Tyri à Confessio Amantis: leituras de uma narrativa singular}
Autor(es):
Carrajana, Paula Mota
Publicado por: Centro de Estudos Clássicos e Humanísticos
URL
persistente:
URI:http://hdl.handle.net/10316.2/39257
DOI:
DOI:http://dx.doi.org/10.14195/978-989-26-1229-4_15
Accessed : $\quad$ 26-Apr-2023 11:35:17

A navegação consulta e descarregamento dos títulos inseridos nas Bibliotecas Digitais UC Digitalis, UC Pombalina e UC Impactum, pressupõem a aceitação plena e sem reservas dos Termos e Condições de Uso destas Bibliotecas Digitais, disponíveis em https://digitalis.uc.pt/pt-pt/termos.

Conforme exposto nos referidos Termos e Condições de Uso, o descarregamento de títulos de acesso restrito requer uma licença válida de autorização devendo o utilizador aceder ao(s) documento(s) a partir de um endereço de IP da instituição detentora da supramencionada licença.

Ao utilizador é apenas permitido o descarregamento para uso pessoal, pelo que o emprego do(s) título(s) descarregado(s) para outro fim, designadamente comercial, carece de autorização do respetivo autor ou editor da obra.

Na medida em que todas as obras da UC Digitalis se encontram protegidas pelo Código do Direito de Autor e Direitos Conexos e demais legislação aplicável, toda a cópia, parcial ou total, deste documento, nos casos em que é legalmente admitida, deverá conter ou fazer-se acompanhar por este aviso.

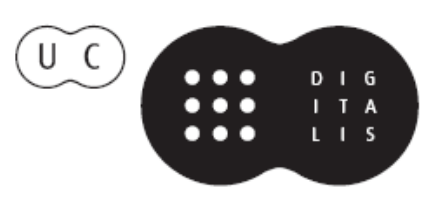


FRANCISCO DE OLIVEIRA

PAOLO FEDELI

DELFIM LEÃO

Coordenadores

\section{- ROMANCE ANTIGO ORIGENS DE UM GÉNERO LITERÁRIO}

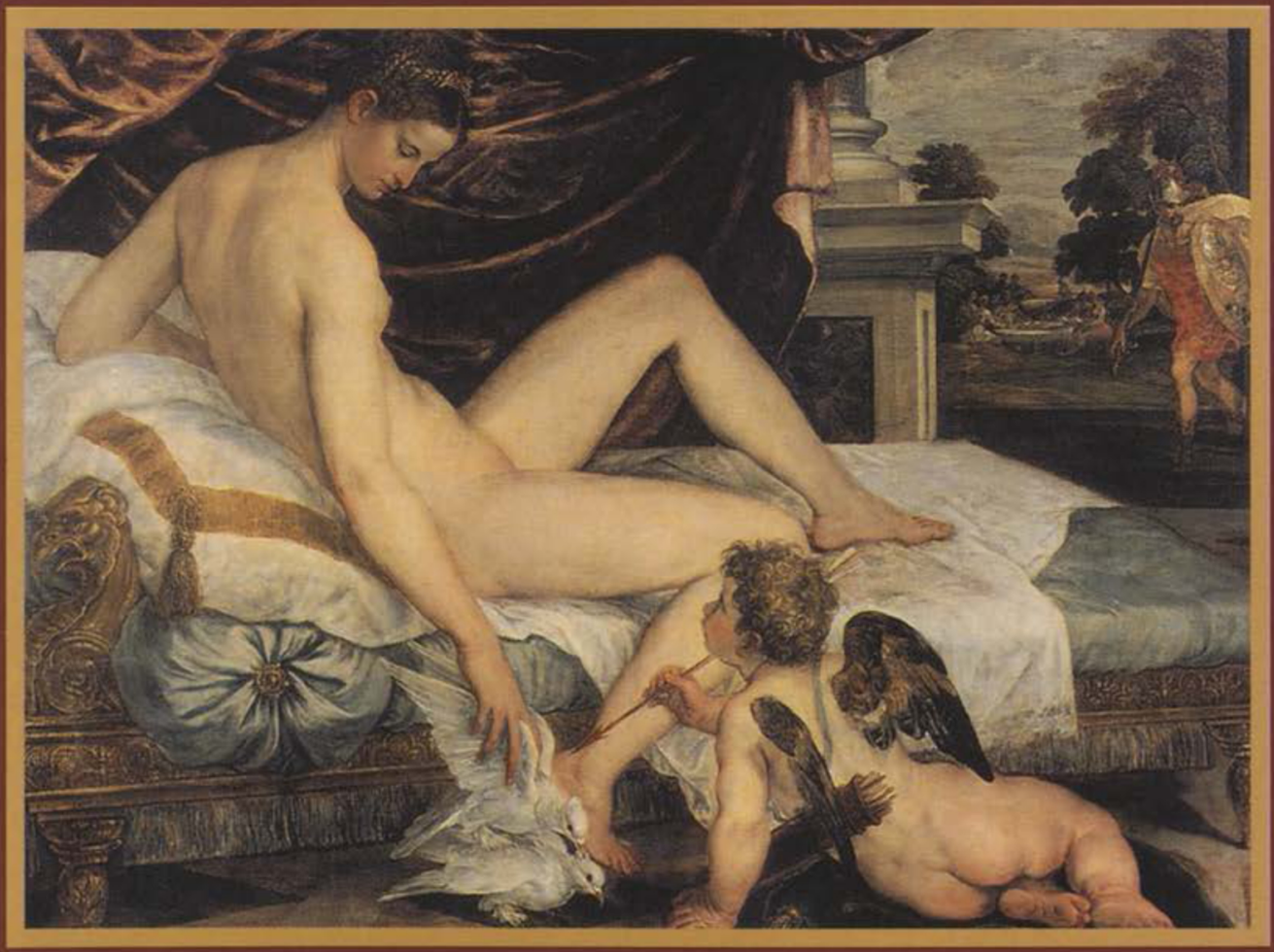

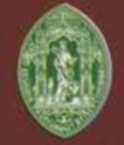

Universidade de Coimbra

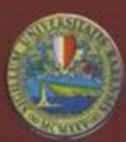

Università degli Studi di Bari

COIMBRA

2005 


\title{
DA HISTORIA APOLLONII REGIS TYRI À CONFESSIO AMANTIS: LEITURAS DE UMA NARRATIVA SINGULAR
}

\author{
PAUla MOTA CARRAJANA \\ Universidade dos Açores
}

A Historia Apollonii regis Tyri tal como nos é transmitida pelas duas mais antigas versões conhecidas - as Redactiones A e B - terá sido composta por volta do séc. V ou VI d. C. ${ }^{1}$ Na sua génese estaria um texto anónimo, hoje desaparecido, e sobre o qual os estudiosos têm expendido opiniões muito diversas. A língua em que terá sido escrito esse texto matricial (a latina ou a grega?) e a data da sua composição são as questões acerca das quais os filólogos mais têm discordado. ${ }^{2}$

Já sobre as características formais e estruturais do texto, praticamente não existem vozes dissonantes: os autores têm sido unânimes em assinalar a monotonia e a simplicidade que caracterizam a prosa $^{3}$ de uma Historia parca em detalhes psicológicos e redutora no que à

${ }^{1}$ A investigação subjacente a este artigo foi por nós desenvolvida no âmbito da elaboração do trabalho de sintese atinente a Provas de Aptidão Pedagógica e Capacidade Científica (cf. CARRAJANA, 2003). Cumpre-nos, por isso, agradecer à Doutora Marília Futre Pinheiro, orientadora desse trabalho, a quem devemos sugestões que em muito o enriqueceram. Ao longo do presente artigo, citaremos passos da tradução portuguesa da Confessio Amantis de John Gower, que até há poucos anos se considerava perdida. $\mathrm{Na}$ demanda dessa tradução, recebemos valiosos auxilios. Ao Doutor Aires Nascimento agradecemos a notícia da descoberta do texto; à Dr. ${ }^{a}$ Isabel Cepeda, a informação do paradeiro do mesmo; aos funcionários da Real Biblioteca do Palacio Real, em Madrid, a facilitação do manuscrito, até hoje não editado, e à Dr." Odilia Gameiro, o complexo e moroso trabalho de transcrição paleográfica.

${ }^{2}$ As duas principais linhas de argumentação sobre estes problemas são encimadas por KortekAAs (1984) e SCHMELING (1988). Para uma sintese das teorias acerca da génese da Historia Apollonii, consulte-se PuCHE LóPEz (1997).

${ }^{3}$ A propósito do estilo desta obra, vejam-se as análises de ARCHIBALD (1991) 12-15 e PUCHE LÓPEZ (1997) 59-69; (1999). Refira-se, em abono da verdade, que, apesar da falta de elaboração que a caracteriza, a prosa da Historia não é totalmente desprovida de figuras de retórica. Sobre os recursos de ornatus presentes na narrativa, vide PuCHE LóPEZ (1997) 59-69 e ARCHIBALD (1991) 15. 
caracterização das personagens diz respeito. A intriga, ingénua e linear, reúne, por vezes de forma algo desconexa, tópicos de variadas tradições literárias e populares, cristalizadas em temas como o incesto, a relação entre pais e filhas, o exercício do poder régio e a prudentia, associada quer à actividade governativa quer à decifração de enigmas. Da leitura do texto resulta, para além disso, a impressão de que nele abundam lacunas e incoerências. ${ }^{4}$

Não obstante, o público, mantendo-se alheio a estas imperfeições, fez da Historia um dos textos mais lidos e apreciados durante a Idade Média e o Renascimento. A popularidade das aventuras e desventuras de Apolónio é, de facto, atestada não só pelo ingente número de manuscritos do texto - cento e catorze, feito raro no âmbito da ficção antiga,$-{ }^{5}$ mas também pela considerável quantidade de alusões que, ao longo de séculos, se lhe foram fazendo - e uma alusão só se justifica se o texto for, à partida, conhecido do público-alvo. É igualmente prova do seu sucesso a significativa abundância de traduções para línguas vernáculas ${ }^{6}$ e a inclusão da narrativa em obras de cariz diverso e de variadas proveniências linguísticas. ${ }^{7}$ Apesar disso, é

4 ARCHIBALD (1991) 63 ss. identifica e comenta as inúmeras contradições existentes na intriga. Na primeira parte do texto, existem, de facto, vários contrasensos: Antíoco, tomado de amores pela filha, receia que o seu crime seja descoberto e propõe, ainda assim, um enigma alusivo ao incesto; Apolónio decifra a charada e é inexplicavelmente deixado partir em liberdade; durante a fuga, demora-se em Tarso mesmo depois de ter sido aconselhado a não o fazer; nessa cidade, e apesar de ser um proscrito, os cidadãos erguem-lhe uma estátua; passado algum tempo, parte de forma precipitada e sem motivo aparente; após a morte de Antíoco, a coroa é-lhe inesperadamente deixada; no momento em que entrega a filha a Estranguilião e Dionisíade, faz um estranho voto, que permanece sem explicação; por fim, parte para o Egipto e dele nada se sabe durante catorze anos. Também nos episódios relativos à história de Tarsia algumas questões ficam sem resposta. Por exemplo, sendo Atenágoras um homem tão poderoso, por que motivo não liberta Tarsia do jugo do alcoviteiro? E como se explica o casamento entre o príncipe de Mitilene e a filha de Apolónio quando nada o fazia prever? $\mathrm{Na}$ verdade, afirma-se apenas que Atenágoras amava Tarsia como se de uma filha se tratasse (Hist. Apol. 36); acerca dos sentimentos que a jovem nutriria pelo príncipe, nada se diz.

${ }^{5}$ Um deles, composto no séc. X ou XI, merece especial referência pelo seu carácter excepcional: ao texto junta-se uma série de trinta e cinco ilustrações alusivas à intriga da Historia.

${ }^{6}$ A Historia foi traduzida, por exemplo, para inglês antigo, francês, dinamarquês, norueguês antigo, castelhano, alemão, checo, holandês, grego, polaco e russo. Há inclusive notícia da recente descoberta de uma tradução para catalão - cf. PUIG (2001).

${ }^{7}$ Sobre as traduções e adaptações da Historia, vide, ARCHIBALd $(1991 ; 1999)$ e ainda KLebs (1899) 325-511, Singer (1974), Robins (1995; 2000) e PUCHE LÓPEZ (1997) 72-82. Para as versões latinas, consulte-se também KORTEKAAS (1990). 
curioso notar que nenhuma das versões mais inovadoras provocou a imitação: foi a narrativa original aquela que continuou a ser glosada. Essa circunstância dever-se-á, porventura, ao facto de a exemplaridade dos textos ser, na Idade Média e no Renascimento, associada à autoridade outorgada pelo passado - a propósito da Historia, Shakespeare sugere mesmo que o seu valor procede da antiguidade: et bonum quo antiquius eo melius. ${ }^{8}$ De qualquer modo, a cada leitura a narrativa tomou direcções semânticas e, por vezes, até genológicas, mais ou menos distintas das do original.

Segundo os princípios teóricos preconizados por Jauss, a obra literária é susceptível de tomar novos sentidos em concomitância com a alteração das condições históricas e sociais da sua recepção. ${ }^{9}$ Pode, portanto, ser 'concretizada' em variados objectos estéticos..$^{10}$ Quer isto dizer que o texto literário é uma obra aberta. ${ }^{11}$ Nele estão contidos inúmeros sentidos e, por isso, várias podem ser as suas interpretações. ${ }^{12}$

Mas a liberdade interpretativa do leitor encontra-se condicionada, por um lado, pela sua 'competência comunicativa', ${ }^{13} \mathrm{e}$, por outro, por 'pontos de indeterminação' ou 'lacunas ${ }^{14}$ inerentes ao próprio texto literário. Estas indeterminações resultam, nas palavras de Aguiar e Silva, «quer da natureza da linguagem verbal, quer da inevitável selectividade da arte literária, quer de uma intenção estética.» ${ }^{15}$ Ao leitor cabe, então, a tarefa de concretizar o texto literário, identificando e preenchendo as lacunas existentes na estrutura do mesmo. ${ }^{16}$

Ora na Historia a indeterminação é uma constante. Se o texto dos sécs. V ou VI é, por um lado, pródigo em aventuras, viagens, amor

${ }^{8}$ Cf. Pericles, I, 10. A propósito desta questão, consulte-se ARCHIBALD (1991) 51.

${ }^{9}$ JAUSS (1978) 21-80 e 123-157; (1989) 235.

${ }^{10}$ Aguiar E Silva (1990) 318-319. Para INGARden (1973), responsável pela formulação primeira de 'concretização', este conceito implica não apenas os actos cognitivos do leitor, mas também as estruturas da obra literária.

${ }^{11}$ ECO (1986).

${ }^{12}$ Porém, como lembra o próprio ECo (1993) 29, «a noção de semiose ilimitada não desemboca na conclusão de que a interpretação não tem critérios. Dizer que a interpretação (como aspecto fundamental da semiose) é potencialmente ilimitada não significa que a interpretação não tenha objecto e que corra à imagem de um rio apenas por sua própria conta. Dizer que um texto não tem potencialmente fim não significa que todo e qualquer acto de interpretação possa ter um final feliz.» Há que atender, segundo ao mesmo autor (1993) 30, à intenção do texto, contida, obviamente, no próprio texto.

\footnotetext{
${ }^{13}$ Aguiar e Silva (1990: 316-317).

${ }^{14}$ INGARDEN (1973) $§ 38$.

${ }^{15}$ Aguiar E Silva (1990) 329.

${ }^{16}$ Vide Aguiar E Silva (1990) 329.
} 
(ou, melhor dizendo, prenúncios de amor), sofrimento, coragem e persistência - tópicos claramente romanescos -, é, pelo outro, generoso em castigos e recompensas - ao jeito de exemplum. Esta amálgama de tópicos resulta num produto singular, formal e semanticamente aberto, e, por isso, susceptível de diversas interpretações e leituras. A forma como essas interpretações foram sendo feitas e como o texto se foi concretizando em diferentes leituras é perceptível nas várias reescritas e traduções. Na verdade, segundo Lefevere e Bassnett, a reescrita, em geral, e a tradução, em particular, constituem um documento da recepção, devendo ser estudadas como tal. ${ }^{17} \mathrm{O}$ tradutor é, afinal, simultaneamente leitor e autor. ${ }^{18}$

As condições históricas e sociais na época medieval e renascentista já não são as dos sécs. V-VI. As cruzadas, o amor cortês e a moralidade cristã são as novas palavras de ordem. E as aventuras de Apolónio vão sendo lidas à luz dessa nova realidade. Ganhando novos significados, são concretizadas em diversos objectos estéticos.

Desde os seus primórdios este relato foi entendido por uns como exemplar e por outros como romanesco. Tanto as versões mais próximas do romance de cavalaria como as de carácter moralizante parecem ter surgido primeiramente no séc. XIII ${ }^{19}$ nos sécs. XV e XVI, a índole das adaptações tornou-se ainda mais variável: enquanto umas enfatizavam os valores de cavalaria, outras davam relevo à moralidade cristã; ao passo que algumas medievalizavam a intriga, outras reintroduziam nela pormenores clássicos. ${ }^{20}$

Segundo cremos, é precisamente na análise dessas adaptações desses novos objectos estéticos - que reside a chave do sucesso da Historia. Interessa-nos, então, compreender por que processos a Historia vai sendo actualizada. Para tal, de entre a panóplia de versões desta narrativa, concentrar-nos-emos em Confessio Amantis, que elegemos por constituir o único episódio de recepção do singular tema de Apolónio no nosso país.

Foi no ano de 1393 que John Gower completou a terceira e última versão da Confessio, cujo assunto é a reeducação amorosa do protagonista, Amante, personagem que se encontra perdida nos seus

${ }^{17}$ Lefevere (1985) E BASSNETT (2001).

${ }^{18}$ Cf. BASSNETT (2001) 306.

${ }^{19}$ Do primeiro caso é exemplo Thidreks Saga af Bern, texto em norueguês antigo da autoria de Dietrich de Berna em que Apolónio aparece como filho do Rei Artur; da segunda tendência é representativo o Libro de Apolonio, poema castelhano anónimo cujo conteúdo foi submetido a um processo de profunda cristianização.

${ }^{20}$ Vide ARCHiBALD (1991) 51. 
sentimentos, não sendo sequer capaz de os identificar. Por esse motivo, Amante é enviado a um confessor, Génio, que se transforma no seu guia espiritual. Génio é um servo da Natureza, e esta, mercê da sua origem divina, é boa por essência. ${ }^{21} \mathrm{O}$ confessor avalia, então, o comportamento humano de acordo com a sua maior ou menor 'naturalidade'. Ao longo do diálogo que mantém com Amante, disserta sobre os crimes perpetrados pelo homem contra a Natureza. O objecto das suas considerações não é apenas o amor contranatura mas também outros vícios. Na verdade, no Livro I, o confessor afirma que exorcizará Amante dos sete pecados mortais ${ }^{22} \mathrm{e}$, à medida que o poema avança, procura imbuir o protagonista do espírito da verdadeira humanitas. Tanto assim é que todo o Livro VII diz respeito à educação de Alexandre, «[...] a lesson which Amans must learn if he is to reclaim and rule the lost kingdom of his soul..» ${ }^{23}$

Desta forma, por meio do artifício da confissão, Amante faz, por um lado, uma reapreciação da Natureza ${ }^{24}$ e, por outro, uma redescoberta de si próprio. Os métodos utilizados para tal são a introspecção e a análise de casos históricos. É nesse contexto que, no Livro VIII, surge a Historia Apollonii. Nesse capítulo, cujo assunto deveria ser à partida a luxúria em todas as suas formas, Génio refere-se brevemente às leis enformadoras do casamento e discorre depois acerca do incesto. À razão pela qual procede desta forma, voltaremos mais tarde. Por agora, consideremos a(s) fonte(s) subjacentes à versão da Historia transmitida por Gower. $\mathrm{O}$ autor inicia o relato da saga do rei de Tiro identificando a "Cronica de Apollonio", inclusa em Pantheon, de Godfrey de Viterbo, como o texto que lhe serviu de referência. ${ }^{25}$ Pantheon é um trabalho enciclopédico, de carácter histórico, composto no séc. XII. Segundo se crê, a "Cronica de Apollonio" tem por base um dos textos da versão $\mathrm{C}$ da Historia. Esta, porém, não é parafraseada, sendo inclusivamente omitidos vários aspectos da intriga: ${ }^{26} \mathrm{o}$

${ }^{21}$ Cf. PECK (1997) xv. Como afirma o autor, esta concepção da personagem espelha a existente em textos anteriores.

${ }_{22}$ Esse Livro tem por tema a soberba; o II versa a inveja; o III, a ira; o IV, a preguiça; o V, a avareza; o Vl, a gula, e o VIII, a luxúria. O Livro VII trata, como veremos, da educação de Alexandre.

${ }^{23}$ PECK (1997) xv.

${ }^{24}$ PeCK (1997) xvi.

25 «Of a Cronique in daies gon,/ The which is cleped Pantheon,/ In loves cause I rede thus,/ Hou that the grete Antiochus/[...] Was coupled to a noble queen,/ And hadde a dowhter hem between" (Confessio, 8, 271-274; 277-278). O texto é citado a partir da edição de PECK (1997).

${ }^{26}$ Veja-se ARCHIBALD (1991) 185. 
enigma proposto por Antíoco é elidido em duas das três Recensiones de Pantheon; não são referidas personagens como Taliarco, Licóride e Helénico; são eliminados alguns pormenores das cenas do bordel e dos reconhecimentos, e a descrição das emoções é ainda mais parca do que na Historia. Ora a Confessio inclui, como veremos, alguns detalhes escamoteados na obra de Godfrey, o que faz supor que Gower tenha conhecido outras versões da narrativa latina.

Certo é que da Confessio foram produzidas inúmeras cópias, tendo a mesma alcançado grande popularidade por toda a Europa. ${ }^{27}$ Durante muito tempo, especulou-se inclusive sobre a recepção da obra de Gower em terras lusas. Vários eram os indícios de que o texto havia sido traduzido para português, ${ }^{28}$ mas do paradeiro dessa tradução nada se sabia, tendo a sua existência chegado a ser posta em causa. ${ }^{29}$ Todavia, este estado de coisas alterou-se quando, em 1995, foi descoberto, na Biblioteca do Palácio, em Madrid, um manuscrito que continha precisamente o tão procurado texto: a versão portuguesa da Confessio Amantis, ${ }^{30}$ cuja edição se encontra ainda a ser preparada. ${ }^{31}$

${ }^{27}$ Consulte-se, a este propósito, DOYLE e PARKES (1978).

${ }^{28} \mathrm{Em}$ primeiro lugar, numa tradução da obra para castelhano, conservada na biblioteca de El Escorial (MS g-II-19), o autor, Juan de Cuenca, faz referência a uma versão portuguesa que teria estado na base do seu trabalho: «Este libro es llamado Confisyón del amante, el cual compuso Joan Goer natural del reino de Inglatierra e fue trasladado al portugués por Roberto Payno, nacido en el dicho reino e clérigo de la ciudad de Lisboa. E éste fue trasladado al castellano por Joan de Cuenca, vecino de la ciudad de Huete» (Confesión, 4.2.19. A edição por nós utilizada é a de Alvar, 1990). Em segundo, essa tradução portuguesa é mencionada por D. Duarte no prefácio do Leal Conselheiro como uma das fontes desta obra: «filhando em esto exemplo daquel autor do Livro do Amante, que certas estorias em el screveo de que se filham grandes boos conselhos e avisamentos» (PIEL, 1942, 7. Sobre esta questão, vide Dionísı, 1995). Por fim, consta, sob o título de $O$ Amante, na listagem dos Livros de Linhagem do mesmo rei D. Duarte - cf. NETO (1956) 117 e NASCIMENTO (1993) 284-285.

${ }^{29}$ Granillo (1985) defendeu inclusivamente que Juan de Cuenca teria elaborado a sua tradução directamente a partir do texto de Gower, tendo para isso contado com a ajuda de um inglês que durante vários anos residira em Portugal. Porém, SANTANO MORENO, num estudo de 1990 (35 ss.), demonstra claramente que a presença de lusitanismos na tradução castelhana comprova que esta foi realizada a partir de uma versão portuguesa.

${ }^{30}$ É CORTIJO OCAÑA (1995) 457 quem noticia o achado. Sobre o mesmo assunto, vide também DEYERMOND (1995) 42. Para uma síntese das questões que se colocam relativamente à génese da tradução portuguesa, cf., por exemplo, MANLY (1929-1930), Martins (1983), Santano Moreno (1991), Cortijo Ocaña (1997) e BuEscu (2001).

${ }^{31}$ Por tal motivo, citaremos o texto em questão a partir do manuscrito II-3088 da Real Biblioteca (Palacio Real, em Madrid). Dado que a cópia com que trabalhámos corresponde à impressão do texto microfilmado, não nos é possível distinguir nos 
No que ao episódio de Apolónio diz respeito, $O$ Amante (ou $O$ Livro do Amante) - assim é conhecida a tradução em língua lusa - é fiel ao texto de Gower, razão pela qual doravante por Confessio designaremos, em simultâneo, os dois textos: o do autor inglês e a respectiva tradução portuguesa. ${ }^{32}$

Já entre a Confessio e a Historia existem diferenças dignas de nota. Comecemos por enunciar as que nos parecem de menor monta e que se resumem a pequenas alterações, decorrentes, quiçá, da necessidade de adequar determinados pormenores a uma realidade diferente da dos sécs. V-VI d. C. Enquanto na Historia (13), o local em que decorrem os jogos promovidos pelo rei de Cirene é o ginásio, na Confessio esse local é «hum campo largo e fromoso?». ${ }^{33}$ Se no texto latino o soberano participa activamente na competição física (13), na adaptação «el rrey» não passa de mero observador. ${ }^{34}$

Para além destas alterações pouco relevantes no contexto da intriga, outras há que assumem grande importância no decurso da acção, chegando algumas a corrigir passos que na Historia são pouco consistentes. No relato latino (7-8), causa estranheza o facto de Antíoco enviar soldados no encalço de Apolónio quando, na verdade, nenhum episódio bélico vem a ter lugar: sobre esses soldados não se volta, aliás, a falar. Ora na Confessio o pérfido rei de Antioquia fica pesaroso com o desaparecimento do príncipe de Tiro, mas acaba por desistir de encontrá-lo. ${ }^{35}$ Outro passo em que a intriga da Confessio é claramente mais coerente do que a da Historia é o da permanência de Apolónio em Tarso. Enquanto no último texto o rei de Tiro se mantém por muito tempo naquela cidade mesmo depois de ter sido aconselhado por Helénico a procurar refúgio em outras paragens (8-11), no primeiro parte imediatamente após o referido conselho. ${ }^{36} \mathrm{Na}$ Historia fica tam-

vários fólios a frente do verso. Assim, situaremos as citações que fizermos apenas no fólio e na coluna. Na nossa numeração, o fol. 1 coincide com o início do conto de Apolónio.

${ }^{32}$ Por uma questão de clareza, na identificação de passos citados ou aludidos, por Confessio referir-nos-emos ao texto de Gower e por $O$ Amante, à tradução portuguesa.

${ }_{33}^{3} O$ Amante, fol. 7, col. 1; cf. Confessio, 8, 689.

${ }^{34}$ O Amante, fol. 7, col. 1; cf. Confessio, 8, 679 ss.

35 «El Rey por hum tempo/ ouve en. ssy por ello muy gram/ pesar. mas quando vyo que a ssua/ sotilleza nom prestou pera acabar/ o que queria de hi en diante abrandou sua yra e non fez dello conta» (O Amante, fol. 4, col. 2; cf. Confessio, 8, 533-536).

${ }^{36}$ «Este Senhor novo por cuydar/ o que lhe seria mjlhor de fazer em es/se caso. dentro en ssy ouve pou/co assesego e fynalmente propôs de sse/ mudar daquel lugar. e 
bém sem explicação o facto, totalmente inesperado, de o reino de Antioquia ser herdado por Apolónio (24). Porém, na Confessio essa circunstância é corrigida. Os mensageiros da morte de Antíoco não fazem qualquer referência ao destino da coroa do falecido monarca e rogam a Apolónio que regresse a Tiro. ${ }^{37}$ Relativamente aos capítulos da Historia que tratam da vida de Tarsia em Mitilene, ${ }^{38}$ uma questão fica igualmente por esclarecer: sendo o príncipe dessa cidade um homem tão poderoso, e tendo conhecimento do sofrimento da jovem, por que motivo a não liberta do jugo do alcoviteiro? A verdade é que na Confessio essa incongruência é resolvida, pois Atenágoras, o príncipe, só surge na acção no momento em que o navio de Apolónio chega ao porto de Mitilene. ${ }^{39}$ Em outro episódio ainda este texto se revela mais consistente do que o latino. Quando desembarca em Tiro, o enviado de Antíoco, ao contrário do que acontece na Historia (7), disfarça-se para não correr o risco de ser reconhecido. ${ }^{40}$

Conforme antes afirmámos, a narrativa original atribui pouca importância às emoções, sendo, por isso, parca em detalhes psicológicos. Já na Confessio o mesmo não acontece. Em várias ocasiões a acção é suspensa e a narração dos factos dá lugar a comentários a propósito dos sentimentos e atitudes das personagens. Um dos mais interessantes exemplos do que acabámos de afirmar é a explicitação do motivo que conduz Antíoco a um comportamento incestuoso. ${ }^{41}$ Mas existem muitos outros casos em que a Confessio revela uma clara preocupação com a psicologia e os comportamentos humanos. A reacção dos Tírios à partida de Apolónio, parcamente aflorada na Historia (7), recebe naquela obra um tratamento mais cuidado. As atitudes são

hyr bus/car mais longe. alguã outra ter/ra stranha en que stevesse por hum/ tempo» (O Amante, fol. 5, col. 2; cf. Confessio, 8, 593-596).

${ }^{37}$ «E porem de/ Senhor em nome de toda a vossa/ terra e Senhorio de Tyro de sseu/ mandamento vos suplicamos que leixan/do todallas outras cosas vos/ praza de vijirdes visitar nossos/ sojeytos e verdadeiros servjdores/ com outros vossos parentes que junta/mente com grande soydade. stam/ aguardando pella vossa hida» (O Amante, fol. 12, col. 2; cf. Confessio, 8, 1003-1010).

${ }^{38}$ Vide Hist. Apol. 33 ss.

${ }^{39}$ «O ssenhor da cidade cujo nome era/ Athenagoras. stava hi enton qua/ndo a naao entrou o qual mandou logo aparelhar hua barca pera hir/ veer. que naao era e que gente vynha// em ella» (O Amante, fol. 26, col. 2 - fol. 27, col. 1; cf. Confessio, 8 , 1621-1625).

${ }^{40}$ "por tal de nom/ seer conhecido das gentes que hi moravom. mudou os vestidos» ( $O$ Amante, fol. 4, col. 2; cf. Confessio, 8, 520-521).

${ }^{41}$ Para tal facto chama a atenção ARCHIBALD (1991) 192. Atente-se no passo em causa: «por a franqueza da ssua carne $\mathrm{m} /$ uytos caae em pecado» ( $O$ Amante, fol. 2 , col. 1; cf. Confessio, 8, 289). 
relatadas, os sentimentos, explicitados, e nem mesmo os clamores são esquecidos. ${ }^{42}$ Os efeitos que o amor por Apolónio provoca na filha do rei de Cirene, sendo descritos no texto latino de forma esparsa, por meio de duas ou três expressões tomadas de empréstimo da Eneida (18), merecem na Confessio uma tirada, relativamente longa, que, uma vez mais, contempla sentimentos e atitudes. ${ }^{43}$ Também no episódio da morte (aparente) da mulher de Apolónio, as reacções das personagens, neste caso do rei de Tiro, são descritas de forma muito díspar nos dois textos. Enquanto na Historia Apolónio, apesar de contristado, se manifesta preocupado sobretudo com o modo como transmitirá a infeliz notícia ao sogro (25), na Confessio mostra-se profundamente magoado, chegando mesmo a desejar a morte. ${ }^{44}$

Quanto a temas e motivos, aqueles que têm relevo na narrativa matricial são igualmente glosados no texto de chegada. Todavia, a importância que lhes é atribuida nem sempre é a mesma. O motivo do incesto, essencial no relato latino, está também presente na Confessio, sendo o comportamento de Antíoco explicitamente condenado por Génio. ${ }^{45}$ Já o tema da relação entre pais e filhas tem neste último texto

${ }^{42}$ «Leixaram o cantar e dançar e. todo/llos outros sabores. entanto que o prazer e allegria. que sohiam buscar/ todo entom foy tornado em sseu [contrairo]/ assi que pelo noio que cada hum en/ ssy tomou do que era acontecido. to/dos se vestiram de doo. e leixaram/ de fazer as barvas e cortar o cabe/llo. os banhos e stufas. per toda a/ villa foram carrados. ca nom a/vya hi criatura que sabor ouvesse/ de jogar nem de tomar prazer./ mas ante choravam todos por ele/ muy dooridamente dizendo Ay Senhor/ que será de nos. pois nosso prinçipe/ e rregedor per quem stavamos man/thudos em nossa onrra. sem prazimento de toda a comunydade tam/ subitamente he assy partido" ( $O$ Amante, fol. 4, col. 1; cf. Confessio, 8, 476-494).

${ }^{43}$ "por amor deste homem de Tyro/ o sseu coraçon aas vezes era quente// como fogo. e outras vezes era frio/ como a neve. e esso meesmo segundo a con/diçon da ssua ymaginaçom ora se/ tornava coorada e outra ora se lh/e de mudava toda sua coor. Mas/ nom embargando os pensamentos desvai/rados que lhe vijnham pello cujda/do. com temor de vergonha feminy/na. sempre guardou muy bem sua no/meada pêro a cabo de tempo o sseu a/mor stava en tal ponto. que ella perdeu o apetito do comer. do bever. e do/ dormyr como aquella que nom sabia/ outro conselho senom por tal da ver logar de cuydar aa ssua voontade/ muytas vezes ficou dentro na sua/ camara e nom sahio della fora» (O Amante, fol. 9, col. 2 - fol. 10, col. 1; cf. Confessio, 8, 845-863)

44 «Oo molher mjnha e todo meu/ prazer. Oo meu sollaz e todo meu/ deseio Tu es minha boa andança/ e todo meu rrellevamento. Pois assy/ he que mjnha ynffortuna quer que tu a/ias de morrer. eu nom ssej pera que a mjnha vjda pera mais longe seia [prolon]/gada. E tu fortuna que agora me/ as fecto. o pior que podes. daqui en dian/te pera ssempre eu te despreçarey. Oo c/oraçon por que nom rrebentas ora/ por tal que em acompanhando [mjnha]/ Senhor a pena que padeço seia mais pe/quena» ( $O$ Amante, fol. 13, col. 2; cf. Confessio, 8, 1062-1070).

${ }_{45} \ll \mathrm{A} / \mathrm{nthioco} \mathrm{com}$ sua soberva que contra/ naturalleza a custumada husou/ de sseu amor por maao dellijto/ rreçebeo depois peendença. como/ aquelle que per 
um papel menos relevante do que no primeiro. O rei de Cirene continua a ser caracterizado como um pai extremoso, e Apolónio, como um pai atento e permanentemente preocupado com o bem-estar da filha. No entanto, da prole de Atenágoras nada se diz. Mais: afirma-se mesmo que ele nunca fora casado. ${ }^{46} \mathrm{Se}$, por um lado, isto acontece em virtude de o príncipe de Mitilene surgir na Confessio numa fase bastante mais avançada da acção, ${ }^{47}$ por outro, deve-se ao facto de o tema do amor no seio de casais ser nesta obra muito mais relevante do que na Historia. Com efeito, enquanto na narrativa latina Atenágoras desempenha o papel de um viúvo que, sendo pai, se apieda da condição de Tarsia, estimando-a como a uma filha (34 ss.) ${ }^{48}$, na Confessio encarna a figura de um jovem príncipe que se toma de amores por Taísa. ${ }^{49} \mathrm{O}$ amor que une Apolónio e a fillha do rei de Cirene é igualmente posto em evidência neste último texto. São dois os momentos da narrativa em que isso acontece: na noite de núpcias e no instante da partida rumo a Tiro, após a notícia da morte de Antíoco. ${ }^{50}$ Recordemos que na Historia Apolónio nunca chega a mostrar-se verdadeiramente apaixonado pela mulher, aparentando sentir por ela apenas a estima que um mestre nutriria pela discípula. ${ }^{51}$ Todavia, na Confessio o rei de

vyngança contra naturale/za subitamente ouve maao acabamento») (O Amante, fol. 33, col. 1; cf. Confessio, 8, 2003-2008).

${ }^{46}$ «E por que / este Athenagoras fosse hum senhor/ rrico [veandante] e de muy grandes a/postamentos elle ata aquel dia nunca fora/ casado" (O Amante, fol. 29, col. 1; cf. Confessio, 8, 1759-1761).

${ }^{47}$ Recorde-se o que acima dissemos sobre este assunto.

${ }^{48}$ Aliás, nunca ao longo da Historia Atenágoras e Tarsia mostram estar apaixonados um pelo outro. Por esse motivo, o seu casamento é, no mínimo, surpreendente.

${ }^{49}$ «E assi the aconteçeo como a/ homem que aynda entom de dias era/ bem novo que the entrou no coraçom/ aquel prazivel noio e allegre pena $d$ amor: a cujo poderio nenhum ho/mem naçido pode rresistyr. o qual/ Senhor penssando en ssy que se El rrey Ihe/ nom fezesse graça que o seu mundo// de todo seria perdido. E buscou tempo/ e lugar como homem a que parecia que/ o coraçom the queria rrebentar por/ fallar a el rrey e a esta virgem sua/ filla pera casar com ella» ( $O$ Amante, fol. 29, cols. 1-2; cf. Confessio, 8, 1762-1772).

${ }_{50}$ «Depois que a noite scura veo este/ Senhor que tijnha guançado o sseu amor/ lançou sse em sua cama com sua/ molher onde antre ssy ouveram com/prido prazer» (O Amante, fol. 11, col. 2; cf. Confessio, 8, 968-972); «Apo/llyno e sua molher [...] entra/rom ambos en a naao. E nom en/bargando que ella entom era pren/nhe. pello grande amor que antre/ ssy avyam nom se queriam partyr» ( $O$ Amante, fol. 12, col. 2; cf. Confessio, 8, 1029-1032).

${ }^{51} \mathrm{Na}$ verdade, a própria princesa assevera que o que a liga a Apolónio é não o amor carnal pelo homem mas a admiração pela sabedoria do mestre: «tu es magister qui docta[m] manu[m] mea[m] docuisti [...] tu es quem admaui non libidinis causa, sed sapientie ducem!» (Hist. Apol., 49, 4-7). Citamos o texto latino a partir de KORTEKAAS (1984). 
Tiro ama de tal forma a filha do rei de Cirene que, como vimos, deseja acompanhá-la até na morte. Para além disso, e ao contrário do que acontece no relato latino, presta-lhe honras fúnebres logo que desembarca em Tiro. ${ }^{52}$ Ainda num outro caso a relação amorosa entre esposos parece ser mais valorizada no texto de chegada do que no matricial: o monarca de Cirene toma a decisão de permitir o casamento da filha em conjunto com a rainha, sua mulher, personagem que no texto latino nem é mencionada. ${ }^{53}$ É, portanto, inegável que o tema do amor não se cinge na Confessio às relações entre pais e filhas; antes se alarga à convivência entre marido e mulher.

Para além do incesto e dos laços parentais, o exercício do poder régio é um dos mais relevantes motivos temáticos da Historia. $\mathrm{O}$ mesmo acontece na Confessio, sobretudo no que a Apolónio diz respeito. Contudo, enquanto no texto original esta personagem só alcança sucesso no papel de rei depois do reencontro com Tarsia (45 ss.), na adaptação as suas capacidades governativas são várias vezes salientadas. ${ }^{54} \mathrm{Na}$ Confessio, Apolónio mostra-se, de facto, um rei mais consciente do que na Historia. Ao invés de partir para o Egipto, depois de deixar a filha em Tarso, abandonando os tronos de Tiro e Antioquia durante catorze anos ${ }^{55}$ o protagonista dirige-se para a sua terra natal, onde retoma o governo. ${ }^{56} \mathrm{E}$ logo após reencontrar a mulher e a filha, a primeira preocupação do rei é regressar a Tiro para aí fazer coroar Atenágoras e Taísa; uma vez mais, ao contrário do que acontece na Historia, encontramos Apolónio em plena actividade governativa. ${ }^{57}$

52 «E ssobre todo nom lhe/ squeçendo sua molher que leixara/ na scuna do mar salgado. rrogo/u thes a todos que aguardassem por/ hum tempo por quanto entendia de fa/zer por memoria della hum say/mento onrrado. O ofiçio do qual foy/muy sollene a maravylla e com/ ysso os sacriffiçios eram muy rri/cos e a ffesta que foy fecta em rreal/leza nom podia seer melhorada/ como aquel que era bem thudo de/ o assy fazer por que em aquel tenpo/ nom avya homem que em bondade te/vesse molher semelhante a ella» (O Amante, fol. 25, col. 2; cf. Confessio, 8, 1557-1566).

${ }^{53}$ Vide O Amante, fol. 11, col. 1; cf. Confessio, 8, 931-932.

${ }^{54}$ A rainha de Cirene só aceita o 'náufrago' Apolónio como genro porque «el assaz de siso e entendimento a/vya pera rreger e governar aquel/ rreyno») ( $O$ Amante, fol. 11, col. 2; cf. Confessio, 8, 986-987).

${ }^{55}$ Cf. Hist. Apol. 28.

56 «tanto que el/ rrey chegou aa cidade de tyro logo/ sem mais tardança fez chamar/ os Senhores de sua terra pera fazer/ cortes. Em as quaes depois que sou/be as cousas todas como sse pasa/rom. em rrazom do rregimento de seu rregno. contou lhas grandes aven/turas e ynffortunas que padecera/ andando fora) ( $O$ Amante, fol. 25 , col. 2; cf. Confessio, 8, 1547-1556).

${ }^{57}$ «[E]l rrey como homem que entom/ tynha conprimento de sseu deseio/ disse que sse queria hir direito pera/ Tyro» (O Amante, fol. 31, col. 1; cf. Confessio, 8, 1877 - 
Ainda uma última vez na Confessio o protagonista aparece no papel de monarca, no momento em que ele e sua mulher recebem o trono de Pentápolis, após a morte do rei de Cirene. ${ }^{58}$ Nesta obra, Apolónio surge, pois, como um governante empenhado, capaz, e, por isso, amado pelo povo, sendo que na Historia o brilho da sua actuação como rei é menor.

Porém, no domínio da sabedoria, o monarca de Tiro destaca-se tanto numa obra como na outra. Na verdade, em ambos os textos Apolónio resolve, sem dificuldade, o enigma proposto por Antíoco $;^{59}$ é convidado para um banquete pelo rei de Cirene, mercê da sua destreza física, ${ }^{60}$ e deslumbra a filha de Arquístrates, mostrando-se versado em várias artes. ${ }^{61}$ Mas o rei de Tiro não é a única personagem relativamente à qual o tema da sapiência é valorizado. Também Tarsia se caracteriza pela prudentia. Tanto na Historia como na Confessio, a filha de Apolónio recebe uma educação esmerada. ${ }^{62} \mathrm{Na}$ narrativa latina, escapa do desejo de quantos a procuram no lupanar graças à sua eloquência (34-35) e enche os cofres do leno pondo em prática os seus dons oratórios (36). No texto adaptado, evita igualmente os pretendentes, desta feita, tornando-se professora das donzelas da cidade. ${ }^{63}$

Intimamente relacionado com o tópico da sabedoria está, na Historia, o da decifração de charadas. São vários os enigmas que Apolónio se vê obrigado a dilucidar. O primeiro, proposto por Antíoco (4), surge igualmente na Confessio, se bem que ligeiramente modificado. ${ }^{64}$

-1878); «El rrey ao sseu poboo mostrou g/rande guasalhado e muy boo [aar/ con] ledo senbrante $\mathrm{E}$ aa cabo de pou/co juntou as gentes de sseu rregno/ e fez cortes geeraaes nas quaes At/henagoras Senhor de Mitellena/ e sua molher Taysa foram coroa/dos» (O Amante, fol. 31, col. 2; cf. Confessio, 8, 1912-1918).

58 «Dep/ois desto a cabo de dous dias ou tres// Avydo primeiro seu conselho asynou hum/ dya certo en que faria cortes geeraaes./ nas quaes per conssentimento de toda aa terra/ el com sua molher por sseu grande/ bem o onrra foram anbos coroados») (O Amante, fol. 33, col. 1; cf. Confessio, 8, 1987-1992).

${ }^{59}$ Vide Hist. Apol. 4; O Amante, fol. 3, col. 1 (Confessio, 8, 423-427).

${ }^{60}$ Cf. Hist. Apol. 13-14; O Amante, fol. 7, col. 1 (Confessio, 8, 704-705).

${ }^{61}$ Consulte-se Hist. Apol. 17-23; O Amante, fol. 8, col. 2 - fol. 9, col. 1 (Confessio, 8, 771 ss.).

${ }^{62}$ Cf. Hist. Apol. 29; O Amante, fol. 22, col. 1 (Confessio, 8, 1327-1333).

${ }^{63}$ «sse hi ouver cavalleiro ou/ Senhor. ou outra pessoa onrrada/ que deseie de teer sua filha bem enssy/nada que eu lhe enssinarey cou/ssas novas de bem. quaes outra mo/lher deste rregno nom sabera fazer» (O Amante, fol. 24, col. 1; cf. Confessio, $8,1461-1466)$.

${ }^{64}$ «Eu com trayçom sou suportado// comendo a carne da mjnha madre cujo marido meu padre eu cuydo/ de buscar. o qual outrossy he filho/ de mjnha molher» (O Amante, fol. 2, col. 2 - fol. 3, col. 1; cf. Confessio, 8, 405-409). 
O segundo, da autoria da filha do rei de Cirene (21), é substituído, na última obra, por uma declaração explícita do amor que a jovem sente por Apolónio. ${ }^{65}$ Os restantes enigmas são propostos por Tarsia aquando do reencontro com o pai (42-43). Embora na Confessio se mencione que a jovem coloca "exemplos e problemas" ao rei de Tiro, nenhum deles é explicitado. ${ }^{66}$ Os diálogos crípticos são, portanto, menos importantes no texto de chegada do que no original, se bem que o enigma acerca do incesto seja basilar, em ambos os textos, para a economia da narrativa: é por ter solucionado o problema colocado por Antíoco que Apolónio é obrigado a fugir e a passar por inúmeras peripécias.

Na Confessio, é a Fortuna quem comanda as aventuras e desventuras dos heróis. ${ }^{67} \mathrm{O}$ próprio narrador se refere a esse facto. ${ }^{68}$ Todavia, face ao texto de Gower, a tradução portuguesa acentua o tom cristão, dado que, de quando em vez, se insiste na ideia da vontade de Deus. ${ }^{69}$ De qualquer modo, em ambas as versões - na de língua inglesa e na tradução portuguesa - a Confessio termina com uma lição de moral explícita: os que «bem amam» são recompensados e os que amam "contra naturalleza» são castigados. ${ }^{70}$ Antíoco alimenta-se da sua própria carne, sofrendo terríveis consequências. Em virtude disso, Génio aconselha Amante a deixar de se centrar apenas em si próprio e nos seus sentimentos. Na verdade, o incesto funciona como uma espécie de metáfora do mal de que Amante padece. Talvez por isso o

${ }^{65}$ «padre Senhor/ per esta carta faço saber aa vossa merçee que sse eu Apollyno nom ouver/ por marido. de todollos outros que no mundo som nom farey conta») (O Amante, fol. 10, col. 2; cf. Confessio, 8, 897-900).

${ }^{66} \mathrm{O}$ Amante, fol. 28, col. 1; cf. Confessio, 1681 ss.

${ }^{67}$ ARCHIBALD (1991) 192 sugere que tal acontece por influência de Pantheon.

68 «[F]ortuna sempre he mudavel e/ nom pode star queda aynda que queira. ca ora he chea de prazer. Outra ora/ he chea de noio. Assy como pella/ storia adiante claramente te será dem/ostrado" (O Amante, fol. 5, col. 2; cf. Confessio, 8, 585-589).

${ }^{69}$ «El rrey magi/nou mujto que poderia significar es/ta visom que the deus demostrara// [...] Entom entendeo elle certamente que a deus/ prouve de the mostrar de noite per vi/son o camjnho que el avya de levar» (O Amante, fol. 29, col. 2 - fol. 30, col. 1; cf. Confessio, 8, 1801 ss.).

${ }^{70}$ «se quiseres pa/rar mentes acharas en como A/nthioco com sua soberva que contra/ naturalleza a custumada husou/ de sseu amor por maao delliyto/ reçebeo depois peendença. como/ aquelle que per vygança contra naturale/za subitamente ouve maao acabamento/ Por esto filho meu tu podes apre/nder que cousa he amar em boa/maneira [...] ca ayuda que ffortuna en sy/ nom Seia stavel ella aas vezes/ he favoravel aaquelles que em amor som verdadeiros» (O Amante, fol. 33, col. 1; cf. Confessio, 8 , 1999 ss.). De acordo com ARCHIBALD (1991) 192, a Confessio é a primeira versão da Historia em que figura uma recapitulação final nestes termos. 
Livro VIII da Confessio se centre apenas nessa forma de Luxúria. ${ }^{71}$ Pelo contrário, Apolónio é o modelo a seguir: tal como o rei de Tiro deambula pelo Mediterrâneo à procura da sua terra natal, Amante viaja no seu íntimo em busca de si próprio.

Assim, segundo Peck, a saga do rei de Tiro é uma brilhante conclusão para a Confessio Amantis. ${ }^{72}$ Apolónio mantém a integridade, apesar das dificuldades por que passa, e acaba por ser rei e senhor de todos os seus domínios. O exílio espiritual de Amante deverá, portanto, terminar da mesma forma. ${ }^{73}$

$\mathrm{Na}$ Confessio, o próprio Génio afirma que as aventuras do rei de Tiro devem ser entendidas como modelares. ${ }^{74}$ Estamos, de facto, perante um assumido exemplum. ${ }^{75}$ Como vimos, de certo modo, a Historia já trazia em. si os gérmenes deste género. Embora não houvesse nesse texto uma moral explícita, a verdade é que nele encontramos dois padrões de comportamento distintos, sendo um - o de Apolónio, de Atenágoras e do rei de Cirene - recompensado, e o outro - o de Antíoco - punido. Mas da narrativa latina fazem igualmente parte temas como viagens, aventuras e amor, ou, pelo menos, vislumbres de amor. Na realidade, tal como se disse acima, vários tradutores e adaptadores medievais e renascentistas juntaram a esses tópicos aqueles que na Historia se adivinhavam, não se encontrando, todavia, claramente definidos. Referimo-nos, sobretudo, aos motivos amorosos e bélicos tão do gosto do romance de cavalaria. ${ }^{76}$ Daqui se conclui que a indefinição formal e semântica da Historia lhe permitiu,

${ }^{71}$ Cf. PECK (1997) xxii. Como justificação para o facto de a Luxúria se cingir, afinal, ao incesto, o autor defende também que aquele pecado mortal havia sido já tratado, em capítulos anteriores, a propósito de outras faltas capitais (ibidem).

${ }^{72}$ PECK (1997) xxv.

${ }^{73}$ Vide PECK (1997) xxvi.

74 «E po [sic] exemplo e rre/membrança dos que bem amam esta/ sua vjda foy posta em Cronyca/ por tal que elles fossem certos que o seu/ amor na fym será mostrado que grando/ he» (O Amante, fol. 33, col. 1; cf. Confessio, 8, 1999-2002). Conforme afirma ARCHIBALD (1991) 192, esta é a primeira vez em que a Historia é explicitamente apresentada como um exemplum moral.

${ }^{75}$ Género literário menor que se integra no discurso exemplar medieval. Pela voz de um mestre, pretende-se apresentar, através de um precedente histórico, um modelo imitável. Sobre esta questão, vide JAUSS (1989, "Prospeto dei generi letterari minori del discorso esemplare nel Medioevo"). No caso da tradução portuguesa, a moral do texto tende a aproximar-se da do cristianismo.

${ }^{76}$ A teoria, por nós perfilhada, de que o texto latino continha já os gérmenes de 'exemplum' e de 'romance' (em particular, de romance de cavalaria) é defendida por ARCHIBALO (1991) 84. 
de facto, ser continuamente relida e actualizada, num processo de revitalização de tópicos subentendidos, de preenchimento de lacunas e de explicitação de indeterminações. Neste fenómeno reside, possivelmente o maior segredo da popularidade da Historia Apollonii. ${ }^{7}$

Para além disso, à semelhança do que acontece com o Romance de Alexandre, trata-se de uma obra anónima, entendida como popular, e, por isso, como património comum. ${ }^{78}$ Desta forma, os copistas sentiam-se na liberdade de introduzir na narrativa alterações, eliminando algumas passagens e acrescentando ou remodelando outras. Tornava-se, portanto, possível modelar o texto de acordo com o gosto e os padrões literários das diferentes épocas, o que constitui mais um trunfo na história da pervivência da saga de Apolónio.

Todavia, a narrativa latina continuou, na Idade Média e no Renascimento, a ser copiada sem quaisquer alterações, o que indica que a intriga "was satisfying as it stood". ${ }^{79}$ A que se deverá, então, tal sucesso? Provavelmente ao tema do incesto que funciona como uma captatio bastante eficaz. ${ }^{80} \mathrm{Na}$ verdade, é sintomático que nenhuma das versões do relato tenha eliminado o episódio de Antíoco. Pelo contrário, em todas elas as aventuras do rei de Tiro e de sua filha vêm na sequência dos actos do malvado rei de Antioquia.

Assim, convertidos de inimigos em aliados, o anonimato, o insólito episódio de incesto e a indefinição conceptual e estrutural da intriga fizeram da Historia Apollonii regis Tyri uma das narrativas mais glosadas de todos os tempos, uma verdadeira Historia in fieri...

${ }^{77}$ Cf. PUCHE LÓPEZ (1997) 81-82, que apresenta relativamente a esta questão um claríssimo raciocínio.

${ }^{78}$ Acerca deste argumento, vide PUCHE LóPEZ (1997) 81.

${ }^{79}$ ARCHIBALD (1990) 132.

${ }^{80}$ Cf. PuCHE López (1997) 80. De acordo com ArChibald (1991) 99-100, as histórias de incesto eram, de facto, muito populares na Baixa Idade Média, em virtude dos intensos debates que juristas e teólogos mantiveram nessa época a propósito das leis do matrimónio. Da mesma autora, consulte-se, sobre este assunto, o estudo de 1989. 


\section{Bibliografia}

A. I. DOYLE, Malcolm B. PARKes, "The production of copies of the Canterbury Tales and the Confessio Amantis in the early fifteenth century", in M. B. Parkes, A. G. Watson (eds.), Medieval Scribes, Manuscripts \& Libraries. Essays presented to N. R. Ker (London, Scolar Press, 1978) 163-210.

Aires A. Nascimento, "As Livrarias dos Príncipes de Avis", in Biblos LXIX, Actas do Congresso Comemorativo do $60^{\circ}$ Centenário do Infante D. Pedro (1993) 265-287.

Alan D. Deyermond, "The Lost Literature of Medieval Portugal", in T. F. Earle, N. Griffin (eds.), Portuguese, Brazilian and African Studies. Studies presented to Clive Willis on his retirement (Warminster, Aris and Phillips, 1995) 39-49.

Ana Isabel BuEscu, "A Confessio Amantis de John Gower na livraria do rei D. Duarte", Actas do I Congresso Internacional de Estudos Anglo Portugueses (Lisboa, 2001) - consultado em http://www.fcsh.unl.pt/congresso ceap/.

André Lefevere, "What Is Written Must Be Rewritten, Julius Caesar: Shakespeare, Voltaire, Wieland, Buckingham", in T. Hermans (ed.), Second Hand: Papers on the Theory and Historical Study of Literary Translation (Antuérpia, 1985).

Antonio CorTiJo OCAÑa, "La Traducción Portuguesa de la Confessio Amantis de John Gower”, Euphrosyne, Nova Série XXIII (1995) 457-466.

Antonio Cortijo Ocaña, "O Livro do Amante: The Lost Portuguese Translation of John Gower's Confessio Amantis (Madrid, Biblioteca de Palacio, MS II-3088)", Portuguese Studies 13 (1997) 1-6.

Bernardo SANTANO MoReno, "The Fifteenth-Century Portuguese and Castilian Translations of John Gower, Confessio Amantis", Manuscripta 35 (1991) 23-34.

Bernardo Santano Moreno, Estudio sobre Confessio Amantis de John Gower y su versión castellana, Confisyon del Amante de Juan Cuenca, prólogo de R. López Ortega (Cáceres, Universidad de Extremadura, 1990).

Elena Alvar (ed.), Manuel Alvar (prólogo), John Gower. Confesión del Amante. Traducción de Juan Cuenca (s. XV) (Madrid, Anejos del Boletín del a Real Academia Española, 1990).

Elimar KLEBS, Die Erzählung von Apollonius aus Tyrus: eine geschichtliche Untersuchung über ihre lateinische Urform und ihre späteren Bearbeitungen (Berlin, Reimer, 1899).

Elisabeth ARCHIBALD, "Apollonius in the Middle Ages and Renaissance", in H. Hofmann (ed.), Latin Fiction. The Latin Novel in Context (London-New York, Routledge, 1999) 229-237.

Elisabeth ARCHIBALD, "Apollonius of Tyre in Vernacular Literature: Romance or Exemplum?", in H. Hofmann (ed.), Groningen Colloquia on the Novel, vol. III (Groningen, Egbert Forsten, 1990) 123-137.

Elisabeth ARCHIBALD, "Incest in Medieval Literature and Society", Forum for Modern Language Studies, vol. XXV, no. 1 (1989) 1-15.

Elisabeth ArChibald, Apollonius of Tyre: Medieval and Renaissance Themes and Variations (Woodbridge, D.S. Brewer, 1991). 
Gareth Schmeling (ed.), Historia Apollonii regis Tyri, Bibliotheca Teubneriana (Leipzig, Teubner, 1988).

George A. A. KortekaAs (ed.), Historia Apollonii regis Tyri. Prolegomena, Text Edition of the two Principal Latin Recensions, Bibliography, Indices and Appendices, Medievalia Groningana 3 (Groningen, Bouma's Boekhuis, 1984).

George A. A. KORTEKAAS, "The Latin Adaptations of Historia Apollonii regis Tyri in Middle Ages and the Renaissance", in H. Hofmann (ed.), Groningen Colloquia on the Novel, vol. III (Groningen, Egbert Forsten, 1990) 103-122.

Hans R. JAuss, Alterità e Modernità della Letteratura Medievale, Nuova Cultura 10, apresent. por C. Segre, trad. por M. ${ }^{a}$ Andreoti e R. Venuti (Torino, Bollati Boringhieri, 1989).

Hans R. JAuss, Pour une esthétique de la réception, trad. por C. Maillard, pref. por J. Starobinski (Paris, Gallimard, 1978).

Jaume de PUIG, "Més nous textos catalans antics del a biblioteca Capitular y Colombina de Sevilla", in J. i Espelt, ATCA 20 (2001) 1 da web (consultado em http://www.iec.es/institucio/seccions/FilosofiaiCienciesSocials/manuscrits.htm).

João Dıonisıo, "Uma abelha no prólogo sobre um desejo formulado no início do Leal Conselheiro, de D. Duarte", Revista da Biblioteca Nacional 10 (1995) 7-22.

John M. MANLY, "On the question of the Portuguese translation of Gower's Confessio Amantis", Modern Philology 27 (1929-1930) 467-472.

Joseph M. PIEL (ed.), Leal Conselheiro (Lisboa, Impr. Portugal-Brasil, 1942).

L. Granillo, "Las traducciones de Confessio amantis: Historiografia de una ficción medieval”, Investigación Humanistica: Filosofia, Historia, Literatura y Lingüistica 1 (1985) 175-193.

Maria Carmen PuCHE LÓPEZ, "I. Historia del texto de la Historia", "II. La Historia e sus protagonistas", "El latín de la Historia Apollonii", "Pervivencia de la Historia Apollonii regis Tyri", in Historia de Apolonio rey de Tiro, trad. (Madrid, Akal/ Clásica, 1997) 13-82.

Maria Carmen PuChe López, "Notas de Estilo a Propósito de la Historia Apollonii Regis Tyri", in A. M. Aladama, M. F. Barrio, M. Conde, A. Espigares, M. J. López de Ayala (eds.), La Filologia Latina hoy. Actualización y perspectivas I, (Madrid, Sociedad de Estudios Latinos, 1999) 237-245.

Mário MARTINS, "Um poema ovidiano de John Gower e a sua tradução do português para o castelhano", Estudos de Cultura Medieval III (Lisboa, Edições Brotéria, 1983) 95-144.

O Amante, MS II-3088 (Madrid, Biblioteca do Palácio).

Paula M. CARrajana, Historia Apollonii regis Tyri: et bonum quo antiquius eo melius. Recepção e popularidade de um tema singular, trabalho de sintese apresentado no âmbito de Provas de Aptidão Pedagógica e Capacidade Científica (Ponta Delgada, Universidade dos Açores, 2003).

Roman Ingarden, A obra de arte literária, trad. por A. E. Beau, M. ${ }^{a}$ C. Puga, J. Barrento, pref. por M. Saraiva (Lisboa, F. C. Gulbenkian, 1973).

Russell A. PECK (ed.), John Gower. Confessio Amantis, reimpr. (Toronto-BuffaloLondon, University of Toronto Press, 1997). 